\title{
Uma Análise Comparativa dos Perfis Feminino e Masculino nos cursos de Computação do Brasil
}

\author{
Alice Barbosa, Hélen Abdala, Érica Gallindo, Reinaldo Braga, Carina Oliveira
}

\author{
${ }^{1}$ Laboratório de Redes de Computadores e Sistemas (LAR) \\ Programa de Pós-Graduação em Ciência da Computação (PPGCC) \\ Instituto Federal de Educação, Ciência e Tecnologia do Ceará (IFCE) - Aracati e Fortaleza
}

\begin{abstract}
In recent years, the percentage of enrollments of female students in Higher Education has remained slightly higher than that of males. However, the scenario is different when analyzing only enrollments in Computing courses: the enrollments of female students are much lower than those of males. In order to present nuances of the addressed question, this work analyzes the set of students entering Computing courses in Brazil from 2010 to 2017. The purpose is to compare, in several aspects, the female and male profiles, such as the admission per year, enrollment situation, ethnicity and regional distribution. The gender disparities pointed out reinforce the need for more actions and discussions on the subject.
\end{abstract}

Resumo. Nos últimos anos, o percentual de matrículas de estudantes do sexo feminino no Ensino Superior se manteve levemente superior ao do sexo masculino. Porém, o cenário é diferente quando se analisam somente as matrículas em cursos de Computação: as matrículas de estudantes do sexo feminino são bem inferiores às do masculino. Buscando evidenciar nuances da questão abordada, este trabalho realiza uma análise do conjunto de ingressantes em cursos de Computação no Brasil no período de 2010 a 2017. O propósito é comparar, sob vários aspectos, o perfil feminino e masculino, como o ingresso por ano, situação de matrícula, etnia e distribuição regional. As disparidades de gênero apontadas reforçam a necessidade de mais ações e discussões na temática.

\section{Introdução}

Nos últimos anos, várias ações governamentais vêm contribuindo para o aumento de ingressantes em cursos presenciais de graduação no país. Analisando os dados do último Censo da Educação Superior, publicado anualmente pelo Instituto Nacional de Estudos e Pesquisas Educacionais Anísio Teixeira, do Ministério da Educação (INEP/MEC), observa-se que foram realizadas 2.041.136 novas matrículas em 2019 contra 1.643.298 em 2010, resultando em um aumento de 24,2\% em 9 anos.

Dentre os ingressantes em 2019, 1.125.522 estudantes eram do sexo feminino, representando 55,2\% do total daquele ano. Entretanto, ao se avaliar os dados de ingresso nesse mesmo ano por área do conhecimento, percebe-se que esta predominância feminina não ocorre de maneira uniforme, sendo eminentemente masculinas. Por exemplo, em 2019, nas áreas de Computação e Tecnologia da Informação e Comunicação (TICs) e Engenharia, Produção e Construção, o sexo masculino representa, respectivamente, $86,4 \%$ e $62,7 \%$ do total de ingressantes [INEP 2019]. 
Dentre outros, os cursos vinculados à Computação e TICs são os responsáveis pelas soluções tecnológicas presentes em problemas de diversas áreas e atividades humanas, e proporcionam oportunidades de emprego e a introdução de jovens em um mercado globalizado e de alta competitividade. No Brasil, por exemplo, dentre as quinze profissões emergentes em 2020 mapeadas pelo LinkedIn, nove estão diretamente relacionadas às TICs [LinkedIn 2020].

Porém, apesar da demanda crescente por profissionais de TIC, em 2019, somente 13,6\% dos ingressantes da área de Computação e TICs foram mulheres. O cenário brasileiro acompanha o internacional: dados do National Center for Women \& Information Technology (NCWIT) mostram que no ano de 2020 as mulheres representavam apenas $25 \%$ das ocupações relacionadas à Computação [NCWIT 2021]. Ainda segundo o NCWIT, nos Estados Unidos, somente $29 \%$ dos bacharéis em Computação e Ciência da Informação graduados em 2019 são mulheres.

De fato, muitas mulheres ainda excluem a possibilidade de seguir uma carreira na área de TIC devido à falta de conhecimento de princípios básicos nos quais as novas tecnologias se baseiam, além do tradicional pensamento que costuma associar a área a uma suposta "vocação masculina". Além disso, há ainda fatores históricos e culturais, com consequências até os dias atuais, que contribuem para afastar as mulheres dessa área de estudo.

A existência de vários estudos em âmbito nacional e internacional ratificam a relevância do tema, e, por outro lado, dão prova de que, não obstante a igualdade de gênero ser uma meta mundial, a sua concretização ainda é um grande desafio, sendo necessário o esforço dos mais diversos atores sociais, inclusive de membros dos poderes públicos (Legislativo, Executivo e Judiciário), Ministério Público, organizações não governamentais e da própria sociedade civil. Nesse sentido, as escolas, as universidades e os institutos federais também têm um papel fundamental para a concretização da igualdade de gênero, não apenas na formação do estudante, mas na vivência diária dentro das próprias instituições [Oliveira et al. 2019].

Como contribuição na direção de evidenciar nuances da questão abordada, o presente trabalho apresenta os resultados de uma análise realizada sobre o conjunto de estudantes ingressantes em cursos de Computação presenciais no Brasil, entre os anos de 2010 e 2017 (a justificativa para escolha desse período é apresentada na Seção 2), com o propósito de observar, sob vários aspectos, os perfis dos estudantes dos sexos feminino e masculino. A partir do sexo dos estudantes, são comparados fatores como o percentual de ingresso, situação de matrícula, etnia e distribuição regional.

O presente artigo está estruturado da seguinte forma: após a introdução, apresentase a estratégia metodológica utilizada na realização desse trabalho. Em seguida, apresentam-se os resultados e algumas discussões sobre eles, bem como algumas conclusões sobre o tema abordado.

\section{Metodologia}

Este trabalho tem como base uma pesquisa de abordagem quantitativa que analisa as matrículas de ingressantes em cursos de graduação presencial de Computação, com o intuito de realizar uma comparação entre os perfis dos estudantes do sexo feminino e 
masculino. Para isso, foi utilizado o Censo da Educação Superior como fonte de dados por ele dispor de:

- Microdados por estudante, com informações de curso, instituição e situação da matrícula;

- Informações de vários anos permitindo uma análise longitudinal e

- Um código de identificação única por aluno.

O Censo da Educação Superior é uma coleta de dados informados anualmente pelas Instituições de Ensino Superior (IES), reunindo informações sobre os cursos, estudantes e docentes. A coleta dos dados é realizada de acordo com o que estabelece o Decreto $\mathrm{n}^{0}$ 6.425, de 4 de abril de 2008. Anualmente, o INEP disponibiliza os microdados contendo os registros da coleta mais recente. Os microdados do INEP representam o menor nível de desagregação de dados informados. Por meio deles, é possível obter um amplo panorama da educação brasileira e, como importante ferramenta de transparência, é certamente um rico acervo sobre a educação de graduação no Brasil.

Para manter a confidencialidade dos dados pessoais dos estudantes, o INEP gerava, até 2017, um único código de identificação por registro de estudante (co aluno) a partir de dados pessoais informados pela IES quando do preenchimento do Censo. A partir de 2018, o INEP alterou o código de identificação, gerando um código novo a cada edição. Como o co aluno era mantido inalterado a cada edição do Censo até 2017, tornou-se possível o acompanhamento longitudinal do indivíduo (somente até 2017), independente da IES a qual ele esteja vinculado [INEP 2017]. Como este trabalho tem um olhar do estudante no curso, o tempo considerado foi 2010 a 2017, tendo sido criada uma chave de acompanhamento para cada um a partir das variáveis co curso, aluno e ano ingresso.

A realização deste trabalhou deu-se em etapas que trataram desde a obtenção dos dados, oriundos do site do INEP, até a construção de representações visuais dos dados consolidados, conforme descrito nas subseções a seguir.

\subsection{Coleta de Dados}

A primeira etapa consistiu na obtenção dos microdados dos anos de 2010 a 2017, a partir do site do $\mathrm{INEP}^{1}$ que, para cada ano, disponibiliza um conjunto de arquivos contendo as informações acerca daquele censo, tais como: o layout dos dados disponibilizados, as orientações para a tabulação destes dados e os arquivos contendo os microdados propriamente ditos.

Cada arquivo, disponibilizado de forma compactada, contém vários arquivos no formato $\mathrm{csv}^{2}$, dos quais foram utilizados os descritos a seguir:

- DM_IES . CSV: cada linha deste arquivo representa uma IES e seus atributos, tais como: código da IES, nome da IES, sigla, município, UF, categoria administrativa (pública ou privada), organização acadêmica (universidade, instituto, cefet, faculdade ou centro universitário), entre outros.

- DM_LOCAL_OFERTA. CSV: cada linha deste arquivo representa um local de oferta de uma IES, útil quando a IES tem mais de um endereço físico de atuação.

\footnotetext{
${ }^{1}$ http://inep.gov.br/microdados

${ }^{2}$ comma separated value
} 
- DM_CURSO . CSV: cada linha deste arquivo representa um curso ofertado pela IES e seus atributos, tais como: código do curso, nome, códigos da IES e do local de oferta ao qual está vinculado, área $\mathrm{OCDE}^{3}$ no qual o curso está categorizado, etc.

- DM_ALUNO . CSV: cada linha deste arquivo representa uma matrícula realizada por um estudante em um curso de uma IES, contendo atributos como: código INEP do aluno, idade, UF e município de nascimento, situação (cursando, formado, transferido, etc), cor/raça, etc. Cabe destacar que o código INEP de um aluno não altera de um ano para o outro. Desta forma, é possível acompanhar sua trajetória acadêmica ao longo dos anos de censo.

\subsection{Consolidação dos Dados e Seleção de Atributos}

Após a obtenção dos 8 arquivos compactados, um de cada censo de 2010 a 2017, estes foram extraídos e os arquivos DM_ALUNO. CSV de cada ano foram consolidados em um só. Como resultado desta união, obteve-se um arquivo único de alunos 2010-2017, que continha cerca de 50 milhões de linhas.

$\mathrm{O}$ arquivo único de alunos foi então relacionado com os arquivos de curso, IES e local de oferta do censo mais recente considerado no estudo, ou seja, 2017. O arquivo de aluno foi relacionado ao de cursos usando-se o campo co curso, ao de IES usando o campo co ies e ao de local de oferta usando 3 campos: co local oferta, co curso, co ies. Também foi realizado um relacionamento do arquivo de cursos com um arquivo auxiliar, usando o campo co ocde, visto este último conter o nome das áreas OCDE associadas aos cursos.

Após a criação de uma fonte única, foi realizado um filtro para que só restassem nos dados as matrículas associadas aos cursos de Computação. Neste estudo, considerouse como cursos de Computação todos aqueles que continham a palavra "computação"em seu nome. Desta forma, cursos da área Ciências, Matemática e Computação podem ter ficado de fora desta seleção (ex: cursos de Sistema de Informação). Os cursos de Computação foram então agrupados, a partir de seus nomes, em três categorias: i) Ciência da Computação; ii) Engenharia da Computação; e iii) outros.

Por fim, foram selecionados os principais atributos a serem utilizados nas comparações, a saber: co aluno, co curso, ano ingresso, co aluno situacao, co ies e no curso; os quais correspondem, respectivamente, ao código do aluno, código do curso, ano de ingresso do aluno no curso, situação do aluno no ano, código da IES e nome do curso.

\subsection{Uniformização dos Dados}

Ao longo do percurso da pesquisa, em função de algumas variáveis observadas mudarem de nome ou de formato de um ano para outro nos censos, a consolidação dos dados precisou de uma fase posterior de uniformização do layout dos dados alterados de um ano para outro. Assim, vários campos novos precisaram ser criados de forma que o tratamento dos dados fosse realizado de forma única independente do ano do censo avaliado.

\footnotetext{
${ }^{3}$ Organização para a Cooperação e Desenvolvimento Econômico
} 


\subsection{Cálculo dos Indicadores de Fluxo Escolar}

Conforme os dados do Censo, sistematizados neste trabalho, ao se considerar todos os estudantes que iniciaram seus cursos entre 2010 e 2017, tem-se que até o momento, $20.8 \%$ destes concluíram seus estudos enquanto que, por alguma razão, outros 40,5\% já desistiram de continuá-los. Este número de evasão representa 6.6 milhões de estudantes dos cerca de 16.3 milhões que ingressaram neste período.

O fenômeno da evasão escolar tem se evidenciado com um dos grandes desafios nas instituições de ensino brasileiras. O Instituto Federal de Educação, Ciência e Tecnologia do Ceará (IFCE) elaborou um Plano para Permanência e Êxito (PPE) de seus estudantes, tendo como um dos objetivos mapear as causas e motivos que levaram os estudantes a se evadirem, além de propor ações de redução da taxa de evasão [IFCE 2017].

$\mathrm{Na}$ sistematização dos dados dos cursos de Ciência de Computação no país, utilizou-se as mesmas categorias previstas no PPE do IFCE. No IFCE as situações das matrículas são agrupadas sob a ótica do curso no qual o estudante está matriculado, sendo os estudantes então categorizados em três grandes grupos: egressos sem êxito, egressos com êxito ou em curso. A categoria "egressos sem êxito" representa todos aqueles que saíram do curso sem um diploma ou um certificado. Aqueles estudantes que concluíram o curso são classificados como "egressos com êxito" e os que ainda possuem vínculo com o curso são classificados como "em curso".

Esta categorização dos estudantes do IFCE em 3 grandes grupos vem sendo utilizada na instituição desde 2015 [Gallindo 2016]. O INEP publicou uma metodologia de cálculo dos indicadores de fluxo da Educação Superior [INEP 2017] que adotou uma categorização dos estudantes pela situação de matrícula similar à adotada no IFCE desde 2015, apenas adotando uma nomenclatura distinta. Egressos sem êxito, egressos com êxito e em curso que são denominados pelo INEP como desistência, conclusão e permanência, respectivamente.

Dessa forma, cada matrícula de estudante foi categorizada em somente uma das 3 possíveis categorias de situação de matrícula supracitadas, para cálculo posterior dos indicadores de fluxo escolar. Nesse contexto, as 6 situações de matrículas do Censo foram agrupadas em:

1. Em curso (cursando ou trancada);

2. Egressos com êxito (formado) e

3. Egressos sem êxito (desvinculado, transferido ou falecido), referenciados neste trabalho também como "evasão".

Para identificar a situação de matrícula mais recente de cada estudante, utilizouse as chaves descritas anteriormente para rastrear a trajetória do estudante em todos os censos posteriores ao ano de seu ingresso. A situação da matrícula no censo mais recente em que um estudante aparece foi a utilizada para fins de agrupamento em uma das 3 categorias supramencionadas.

\subsection{Construção de Visualizações}

A análise das características em um conjunto de dados permite a descoberta de padrões e tendências que podem fornecer informações valiosas que auxiliam a compreender melhor os dados. Essas características podem ser obtidas por meio da aplicação 
de fórmulas estatísticas, enquanto outras, podem ser observadas por meio do uso de técnicas de visualização [Faceli et al. 2011]. Plataformas de visualização de dados permitem criar visualizações automaticamente ou permitem que os usuários criem suas próprias visualizações [Toasa et al. 2018].

Todo o trabalho de junção de arquivos e preparação dos dados foi realizado em uma ferramenta de Business Intelligence chamada Tableau ${ }^{4}$, que também foi utilizada para a tabulação dos dados e a construção das visualizações. O Tableau é uma ferramenta para exploração de dados de maneira intuitiva e interativa, permitindo que sejam feitas descobertas sobre os dados analisados. Na seção seguinte são apresentadas algumas das visualizações de dados construídas no Tableau durante a realização deste trabalho.

\section{Resultados}

Nesta seção, é apresentada uma análise de vários aspectos comparativos entre os públicos do sexo feminino e masculino que ingressaram em cursos de graduação de Computação no Brasil de 2010 a 2017.

\subsection{Ingressantes por Ano}

A Figura 1 ilustra a distribuição dos ingressantes por ano e sexo nos cursos de Computação no Brasil. Como se pode perceber, no ano de 2010, somente $3.911(14,33 \%)$ dos ingressantes foram do sexo feminino contra $23.374(85,67 \%)$ do sexo masculino. Após experimentar um leve aumento entre 2010 e 2014, os ingressantes do sexo feminino voltaram a cair em 2015, chegando a 2017 com quase o mesmo número absoluto de ingressantes de 2010. Este fato revela uma situação preocupante, pois, ao passo que a demanda por profissionais aumenta, o número de ingressantes mulheres amarga estagnação e até chega a diminuir de um ano para outro.

\begin{tabular}{|c|c|c|c|} 
& Feminino & Masculino & Total geral \\
\hline 2010 & $3.91114 \%$ & $23.37486 \%$ & 27.285 \\
\hline 2011 & $3.83314 \%$ & $23.86286 \%$ & 37.695 \\
\hline 2012 & $4.30214 \%$ & $26.79086 \%$ & 31.092 \\
\hline 2013 & $4.33714 \%$ & $27.70986 \%$ & 32.046 \\
\hline 2014 & $4.64613 \%$ & $31.11487 \%$ & 35.760 \\
\hline 2015 & $4.43513 \%$ & $30.96687 \%$ & 35.401 \\
\hline 2016 & $4.35712 \%$ & $31.16388 \%$ & 35.520 \\
\hline 2017 & $3.88912 \%$ & $29.50988 \%$ & 33.398 \\
\hline
\end{tabular}

Figura 1. Ingressantes em cursos de Computação do Brasil (2010-2017).

\subsection{Situação de Matrícula}

A Figura 2 apresenta o quantitativo de estudantes que ingressaram nos cursos de Computação no Brasil de 2010 a 2017 agrupados pela categoria de suas situações de matrícula. Dessa figura, depreende-se que dos 258.197 ingressantes entre 2010 e 2017,

\footnotetext{
${ }^{4}$ Em 2021, o Tableau completou 9 anos como líder no Quadrante Mágico do Gartner Group para Analytics and Business Intelligence Platforms. Fonte: https://www.tableau.com/reports/gartner
} 
$27.632(10,7 \%)$ concluíram o curso, $126.711(49,1 \%)$ se evadiram e $103.854(40,2 \%)$ ainda estão vinculados de alguma forma às suas instituições de ensino, ou seja, ainda estão cursando ou com o curso trancado.

\begin{tabular}{|c|c|c|c|}
\hline \multirow{4}{*}{ 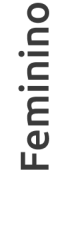 } & Egresso com êxito & $12,2 \%$ & 4.106 \\
\hline & Egresso sem êxito & $50,4 \%$ & 16.989 \\
\hline & Em Curso & $37,4 \%$ & 12.615 \\
\hline & Total & & 33.710 \\
\hline \multirow{5}{*}{ 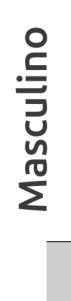 } & Egresso com êxito & $10,5 \%$ & 23.526 \\
\hline & Egresso sem êxito & $48,9 \%$ & 109.722 \\
\hline & Em Curso & $40,6 \%$ & 91.239 \\
\hline & Total & & 224.487 \\
\hline & Total & & 258.197 \\
\hline
\end{tabular}

Figura 2. Situação de matrícula atual dos ingressantes em cursos de Computação no Brasil (2010-2017).

Analisando a evasão por sexo do ingressante, percebe-se que, em termos percentuais, a evasão do público masculino é menor que a do público feminino. Enquanto, das 33.710 mulheres ingressantes, 16.989 se evadiram (50,4\%), do público masculino, dos 224.487 ingressantes, 109.722 homens se evadiram, representando 48,9\% do total de ingressantes deste sexo. Assim, tem-se que, além de ter um número de ingressantes muito inferior ao do público masculino, o índice de evasão do público feminino, de forma geral, é também pior que o do público masculino.

Embora o índice de evasão do público feminino seja mais alto que o do masculino, o percentual de conclusão do público feminino é um pouco superior ao do público masculino. Enquanto 12,2\% do público feminino que ingressou desde 2010 chegou a concluir o curso, este valor é de apenas $10,5 \%$ no caso do sexo masculino. No entanto, em termos quantitativos, o número de concludentes do sexo feminino (4.106) é bem inferior ao masculino (23.526). Um resultado similar pode ser observado para os estudantes em curso: 12.615 estudantes do sexo feminino e 91.239 do sexo masculino.

\subsection{Etnia}

Dos ingressantes analisados neste trabalho, 85.661 se declararam de cor branca, 44.180 de cor parda, 11.215 de cor preta, 3.633 de cor amarela e 842 como indígena, conforme ilustrado na Figura 3. Os demais ou não quiseram informar (não declarada) ou não tiveram sua cor/raça informada pela IES (sem informação) ${ }^{5}$.

A maior parte dos estudantes ingressantes nos cursos de Computação é autodeclarada da cor branca. Destes, $88 \%$ são do sexo masculino e $12 \%$ são do sexo feminino. No entanto, o índice de evasão de ambos os sexos é muito próximo, 44,6\% para o feminino e $42 \%$ para o masculino. Em se tratando de egressos com êxito deste perfil, os valores

\footnotetext{
${ }^{5} \mathrm{Na}$ Figura 3 não são mostrados os ingressantes que possuem no campo etnia o valor "sem informação" ou "não declarada".
} 


\begin{tabular}{|c|c|c|c|c|c|c|c|c|c|c|c|}
\hline \multirow{4}{*}{ • } & \multirow[b]{2}{*}{$\begin{array}{l}\text { Egresso } \\
\text { com êxito }\end{array}$} & \multicolumn{2}{|c|}{ Preta } & \multicolumn{2}{|c|}{ Parda } & \multicolumn{2}{|c|}{ Indígena } & \multicolumn{2}{|c|}{ Branca } & \multicolumn{2}{|c|}{ Amarela } \\
\hline & & $7,7 \%$ & 128 & $7,4 \%$ & 462 & $9,8 \%$ & 11 & $10,5 \%$ & 1.074 & $13,4 \%$ & 75 \\
\hline & $\begin{array}{l}\text { Egresso } \\
\text { sem êxito }\end{array}$ & $42,9 \%$ & 715 & $43,7 \%$ & 2.731 & $33,0 \%$ & 37 & $44,6 \%$ & 4.572 & $44,7 \%$ & 250 \\
\hline & Em Curso & $49,4 \%$ & 823 & $48,9 \%$ & 3.054 & $57,1 \%$ & 64 & $44,9 \%$ & 4.606 & $41,9 \%$ & 234 \\
\hline & Total & & 1.666 & & 6.247 & & 112 & & 10.252 & & 559 \\
\hline \multirow{4}{*}{ 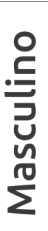 } & $\begin{array}{l}\text { Egresso } \\
\text { com êxito }\end{array}$ & $6,7 \%$ & 640 & $6,2 \%$ & 2.347 & $4,9 \%$ & 36 & $9,0 \%$ & 6.759 & $13,0 \%$ & 399 \\
\hline & $\begin{array}{l}\text { Egresso } \\
\text { sem êxito }\end{array}$ & $43,8 \%$ & 4.178 & $42,2 \%$ & 16.020 & $42,3 \%$ & 309 & $42,0 \%$ & 31.643 & $44,7 \%$ & 1.374 \\
\hline & Em Curso & $49,5 \%$ & 4.731 & $51,6 \%$ & 19.565 & $52,7 \%$ & 385 & $49,1 \%$ & 37.007 & $42,3 \%$ & 1.301 \\
\hline & Total & & 9.549 & & 37.933 & & 730 & & 75.409 & & 3.074 \\
\hline \multicolumn{2}{|c|}{ Total } & \multicolumn{2}{|c|}{11.215} & \multicolumn{2}{|r|}{44.180} & & 842 & \multicolumn{2}{|r|}{85.661} & \multicolumn{2}{|r|}{3.633} \\
\hline
\end{tabular}

Figura 3. Situação de matrícula por etnia dos ingressantes em cursos de Computação do Brasil (2010-2017).

também são muito próximos, mas o índice de conclusão do público feminino de autodeclarados brancos é um pouco maior que o do masculino, 10,5\% e 9\%, respectivamente.

Um comportamento similar ocorre ao analisar a situação de matrícula por etnia dos estudantes autodeclarados de cor preta. Resta claro que, dentre o número de mulheres que se declaram pretas (1.666), existe um alto índice de evasão $(42,9 \%)$ e um baixo índice de conclusão $(7,7 \%)$. Já para o sexo masculino, os índices são bem próximos: $43,8 \%$ de evasão e $6,7 \%$ de conclusão. No entanto, considerando os quantitativos, nota-se que apenas 128 pretas do sexo feminino se formaram entre 2010 e 2017 em cursos de Computação no país, em contraponto com 640 do sexo masculino.

Assim, de forma geral, percebe-se através da Figura 3 que os índices de evasão e conclusão por etnia/raça autodeclarada não se mostraram muito discrepantes entre os agrupamentos analisados.

\subsection{Distribuição Regional}

Ao analisar a distribuição dos ingressantes em qualquer uma das 5 regiões do Brasil (Figura 4), nota-se que o total de ingressantes do sexo masculino é sempre bem superior ao do sexo feminino.

Também é possível constatar que, para ambos os sexos, o Sudeste é a região que apresenta mais estudantes formados (16.314), tendo o público feminino 2.388 formadas (14,7\% das ingressantes) e o público masculino 13.926 formados (12,7\% dos ingressantes). Após o Sudeste, a região Nordeste aparece com mais estudantes formados (3.868): 581 do sexo feminino (9,2\% das ingressantes) e 3.287 do sexo masculino ( $8,3 \%$ dos ingressantes). A região Sul apresenta resultados próximos ao Nordeste com um total de 3.709 estudantes formados, sendo 459 formadas do sexo feminino (9,2\% das ingressantes) e 3.250 do sexo masculino (8,6\% dos ingressantes).

Em se tratando do percentual de egressos sem êxito, estudantes de ambos os sexos apresentam altos índices de evasão independente da região. Salienta-se que nas regiões 


\begin{tabular}{|c|c|c|c|c|c|c|c|c|c|c|c|}
\hline \multirow{4}{*}{ 을 } & \multirow[b]{2}{*}{$\begin{array}{l}\text { Egresso } \\
\text { com êxito }\end{array}$} & \multicolumn{2}{|c|}{ Centro-Oeste } & \multicolumn{2}{|c|}{ Nordeste } & \multicolumn{2}{|c|}{ Norte } & \multicolumn{2}{|c|}{ Sudeste } & \multicolumn{2}{|c|}{ Sul } \\
\hline & & $11,2 \%$ & 360 & $9,2 \%$ & 581 & $10,6 \%$ & 318 & $14,7 \%$ & 2.388 & $9,2 \%$ & 459 \\
\hline & $\begin{array}{l}\text { Egresso } \\
\text { sem êxito }\end{array}$ & $56,2 \%$ & 1.801 & $48,5 \%$ & 3.068 & $46,2 \%$ & 1.382 & $50,4 \%$ & 8.161 & $51,7 \%$ & 2.577 \\
\hline & Em Curso & $32,5 \%$ & 1.041 & $42,3 \%$ & 2.679 & $43,2 \%$ & 1.292 & $34,9 \%$ & 4.655 & $39,1 \%$ & 1.948 \\
\hline & Total & & 3.202 & & 6.328 & & 2.992 & & 16.204 & & 4.984 \\
\hline \multirow{4}{*}{ } & $\begin{array}{l}\text { Egresso } \\
\text { com êxito }\end{array}$ & $8,7 \%$ & 1.925 & $8,3 \%$ & 3.287 & $7,7 \%$ & 1.138 & $12,7 \%$ & 13.926 & $8,6 \%$ & 3.250 \\
\hline & $\begin{array}{l}\text { Egresso } \\
\text { sem êxito }\end{array}$ & $53,4 \%$ & 11.839 & $46,2 \%$ & 18.365 & $49,5 \%$ & 7.295 & $49,2 \%$ & 54.194 & $47,8 \%$ & 18.029 \\
\hline & Em Curso & $38,0 \%$ & 8.427 & $45,5 \%$ & 18.103 & $42,8 \%$ & 6.304 & $38,1 \%$ & 41.935 & $43,6 \%$ & 16.470 \\
\hline & Total & & 22.191 & & 39.755 & & 14.737 & & 110.055 & & 37.749 \\
\hline \multicolumn{2}{|c|}{ Total } & \multicolumn{2}{|c|}{25.393} & \multicolumn{2}{|c|}{46.083} & \multicolumn{2}{|c|}{17.729} & \multicolumn{2}{|c|}{126.259} & \multicolumn{2}{|r|}{42.733} \\
\hline
\end{tabular}

Figura 4. Região dos ingressantes em cursos de Computação do Brasil (20102017).

Centro-Oeste, Sul e Sudeste mais da metade do público feminino evadiu, com $56,2 \%$, $51,7 \%$ e $50,4 \%$, respectivamente.

Em se tratando dos ingressos por Estado, destaca-se que o estado com o maior número de ingressantes é São Paulo. Sozinho, o estado de São Paulo tem 81.315 (31,5\%) do total de ingressantes no Brasil. Em seguida, Minas Gerais com 22.642 alunos $(8,8 \%)$ e o Rio de Janeiro com 15.698 ingressantes.

\section{Conclusões}

Entender o perfil dos estudantes é fundamental para o desenvolvimento adequado de ações para ingresso e incentivo à permanência e êxito escolar. Como contribuição nessa direção, uma análise comparativa do perfil de ingressantes de cursos de Computação do sexo feminino e masculino foi apresentada, destacando, em especial, o ingresso por ano, a situação de matrícula, a etnia e a distribuição regional desses ingressantes.

O resultados apontam que nos cursos de Computação ingressaram cerca de 6,6 vezes mais estudantes do sexo masculino (224.487) que feminino (33.710) entre $2010 \mathrm{e}$ 2017. Além disso, que, em termos de percentual de ingressantes, a evasão do público feminino (50,4\% das ingressantes) é maior do que a do público masculino (48,9\% dos ingressantes), principalmente no Centro-Oeste do país. Também é mostrado que os índices de evasão e conclusão por etnia/raça autodeclarada não são discrepantes entre os agrupamentos analisados.

Como trabalhos futuros, planeja-se expandir a análise para outras áreas do conhecimento, além de aprimorar a proposta através de algoritmos de inteligência artificial. Também pretende-se trabalhar formas de relacionar os dados de 2010 a 2017 com os disponibilizados a partir de 2018 pelo INEP.

\section{Referências}

Faceli, K., Lorena, A. C., Gama, J., and de Carvalho, A. C. P. L. F. (2011). Inteligência Artificial - Uma Abordagem de Aprendizado de Máquina. Rio de Janeiro: LTC. 
Gallindo, d. L. (2016). IFCE em Números: Ferramenta para Suporte às Ações de Permanência e Êxito Discente. https://www.cgu.gov.br/ sobre/institucional/concursos/concurso-de-boas-praticas/ praticas/tp-03-ifce.pdf. [Acesso em: 17-Mar-2021].

IFCE (2017). Plano Estratégico para Permanência e Êxito dos Estudantes do IFCE. https://ifce.edu.br/proen/ensino/ plano-de-permanencia-e-exito.pdf. [Acesso em: 18-Mar-2021].

INEP (2017). Metodologia de Cálculo dos Indicadores de Fluxo da Educação Superior. http://download.inep.gov.br/informacoes_estatisticas/ indicadores_educacionais/2017/metodologia_indicadores_ trajetoria_curso.pdf. [Acesso em: 17-Mar-2021].

INEP (2019). Censo da educação superior 2019. Instituto Nacional de Estudos e Pesquisas Nacionais Anísio Teixeira (INEP). https://download.inep. gov.br/educacao_superior/censo_superior/documentos/2020/ Apresentacao_Censo_da_Educacao_Superior_2019.pdf. [Acesso em: 2-Abr-2021].

LinkedIn (2020). Emerging Jobs Report Brazil. https://business . linkedin . $\mathrm{com} / \mathrm{content/dam/me/business/en-us/talent-solutions/}$ emerging-jobs-report/Emerging_Jobs_Report_Brazil.pdf. [Acesso em: 2-Abr-2021].

NCWIT (2021). National Center for Women \& Information Technology. Disponível em <https://www.ncwit.org/resources/numbers>. [Acesso em: 03-Abr2021].

Oliveira, C., Oliveira, K., Barbosa, A., Ferreira, H., and Neta, M. L. (2019). Projeto DIVAS: desenvolvimento de ações socioeducativas para inclusão, desmistificação e empoderamento da mulher em tecnologias da informação e comunicação. Conexões Ciência e Tecnologia, 13(5):44-54.

Toasa, R., Maximiano, M., Reis, C., and Guevara, D. (2018). Data visualization techniques for real-time information - a custom and dynamic dashboard for analyzing surveys' results. In Iberian Conference on Information Systems and Technologies (CISTI). 